\title{
Cushing's disease and hypertension: in vivo and in vitro study of the role of the renin-angiotensin-aldosterone system and effects of medical therapy
}

\author{
R van der Pas ${ }^{1}$, J H M van Esch², C de Bruin ${ }^{1}$, A H J Danser ${ }^{2}$, A M Pereira ${ }^{3}$, \\ P M Zelissen ${ }^{4}$, R Netea-Maier ${ }^{5}$, D M Sprij-Mooij ${ }^{1}$, I M van den Berg-Garrelds ${ }^{2}$, \\ R H N van Schaik ${ }^{6}$, S W J Lamberts' ${ }^{1}$, A H van den Meiracker ${ }^{2}$, L J Hofland' ${ }^{1}$ and \\ R A Feelders ${ }^{1}$
}

${ }^{1}$ Division of Endocrinology and ${ }^{2}$ Division of Vascular Medicine and Pharmacology, Department of Internal Medicine, Erasmus MC, Room Ee569, Dr Molewaterplein 50, 3015GE Rotterdam, The Netherlands, ${ }^{3}$ Department of Endocrinology and Center for Endocrine Tumors, Leiden University Medical Center, Leiden, The Netherlands, ${ }^{4}$ Division of Endocrinology, Department of Internal Medicine, University Medical Center Utrecht, Utrecht, The Netherlands, ${ }^{5}$ Division of Endocrinology, Department of Internal Medicine, University Medical Center St Radboud, Nijmegen, The Netherlands and ${ }^{6}$ Department of Clinical Chemistry, Erasmus MC, Rotterdam, The Netherlands

\author{
Correspondence \\ should be addressed \\ to $R$ van der Pas \\ Email \\ r.vanderpas@erasmusmc.nl
}

\begin{abstract}
Objective/methods: Cushing's disease (CD) is often accompanied by hypertension. CD can be treated surgically and, given the expression of somatostatin subtype 5 and dopamine 2 receptors by corticotroph pituitary adenomas, pharmacologically. Indeed, we recently observed that stepwise medical combination therapy with the somatostatin-analog pasireotide, the dopamine-agonist cabergoline, and ketoconazole (which directly suppresses steroidogenesis) biochemically controlled CD patients and lowered their blood pressure after 80 days. Glucocorticoids (GC) modulate the renin-angiotensinaldosterone system (RAAS) among others by increasing hepatic angiotensinogen expression and stimulating mineralocorticoid receptors (MR). This study therefore evaluated plasma RAAS components in CD patients before and after drug therapy. In addition, we studied whether cabergoline/pasireotide have direct relaxant effects in angiotensin II (Ang II)-constricted iliac arteries of spontaneously hypertensive rats, with and without concomitant GR/MR stimulation with dexamethasone or hydrocortisone.

Results: Baseline concentrations of angiotensinogen were elevated, while renin and aldosterone were low and suppressed, respectively, even in patients treated with RAAS-blockers. This pattern did not change after 80 days of treatment, despite blood pressure normalization, nor after 4 years of remission. In the presence of dexamethasone, pasireotide inhibited Ang II-mediated vasoconstriction.

Conclusions: The low plasma renin concentrations, even under RAAS blockade, in CD may be the consequence of increased GC-mediated MR stimulation and/or the elevated angiotensinogen levels in such patients. The lack of change in RAAS-parameters despite blood pressure and cortisol normalization suggests persisting consequences of long-term exposure to cortisol excess. Finally, pasireotide may have a direct vasodilating effect contributing to blood pressure lowering.

European Journal of Endocrinology

(2014) 170, 181-191
\end{abstract}

(C) 2014 European Society of Endocrinology Printed in Great Britain 


\section{Introduction}

Cushing's disease (CD) is caused by an adrenocorticotropin (ACTH)-producing pituitary adenoma, which stimulates the adrenal gland to overproduce cortisol. Chronic hypercortisolism is accompanied by all components of the metabolic syndrome and when uncontrolled, $\mathrm{CD}$ is associated with an increased mortality mainly due to cardiovascular disease $(1,2)$. The prevalence of hypertension among patients with $\mathrm{CD}$ has been reported to be $\sim 75 \%$ and is characterized by the absence of the normal nocturnal blood pressure fall $(1,2,3)$. The pathogenesis of hypertension in CD is multifactorial, and glucocorticoid (GC) excess is thought to increase blood pressure via: i) increased mineralocorticoid activity; ii) enhancement of reactivity to vasoconstrictors such as catecholamines, angiotensin II (Ang II), and endothelin-1 (ET-1); iii) increased ET-1 production; iv) inhibition of vasodilator release; and v) modulation of renin-angiotensinaldosterone system (RAAS) activity (3). Data on the role for RAAS in CD are conflicting. Some studies show suppressed levels of renin activity or concentration $(4,5)$ whereas others show normal renin activity $(6,7,8)$ or even elevated renin levels (9). Generally, these are older studies and some of them were carried out in patients with adrenal-dependent Cushing's syndrome (CS) rather than $\mathrm{CD}$. To date, no longitudinal studies have been carried out on RAAS changes in CD before and after treatment.

$\mathrm{CD}$ is primarily treated by transsphenoidal surgery, resulting in remission rates of $60-70 \%$ (10). Medical therapy is indicated in patients with persistent or recurrent $\mathrm{CD}$, whether or not as bridging treatment after radiotherapy (11). Recent studies have shown that corticotroph adenomas often coexpress the somatostatin receptor subtype 5 and dopamine receptor subtype 2 and it has been suggested that these receptors are potential therapeutic targets $(12,13)$. Recently $(13)$, we have carried out a prospective open-label trial, in which stepwise treatment for $\mathrm{CD}$ was applied with the somatostatin-analog pasireotide, the dopamine-agonist cabergoline, and ketoconazole, which suppresses adrenocortical steroidogenesis (11). After 80 days of medical combination therapy, biochemical remission was achieved in almost $90 \%$ of the patients, which was accompanied by a significant decrease in both systolic and diastolic blood pressure (13). Although the decrease in blood pressure might be a direct consequence of decreased cortisol levels, both somatostatin receptors and dopamine receptors have been reported to be present in endothelial cells $(14,15)$. Therefore, pasireotide and cabergoline may directly affect vascular tone.
The first aim of this study was to assess whether biochemical remission induced by pasireotide mono- or combination therapy coincides with changes in plasma concentrations of RAAS components and ET-1 in our CD patients, both throughout the study period and during long-term follow-up. Secondly, we evaluated whether somatostatin analogs and cabergoline directly influence vasoconstriction in vitro using iliac arteries of spontaneously hypertensive rats (SHR) and normotensive Wistar-Kyoto (WKY) rats, in which the effects can be examined using drugs on Ang II-mediated vasoconstriction (16). Concentration-response curves were constructed to Ang II in the absence or presence of dexamethasone or hydrocortisone to mimic the interaction between Ang II type 1 (AT1) receptors and GC receptor (GR)/mineralocorticoid receptor (MR) (17).

\section{Subjects and methods}

\section{Study design}

The study design has been described previously (13). In short, 17 patients (mean age 45.5 years, range 22-67 years, 13 females) with either de novo $(n=12)$, residual $(n=2)$, or recurrent $(n=3) \mathrm{CD}$ were included in four University Medical Centers. The complete study period lasted 80 days. Treatment was initiated with pasireotide $100 \mu \mathrm{g}$ s.c. three times daily (tid). If after 10 days urinary, if free-cortisol excretion (UFC) had not been normalized, the dose was increased to $250 \mu \mathrm{g}$ s.c. tid. In case of persistent hypercortisolism at day 28 , cabergoline was added with pasireotide at day 32 in a dose of $0.5 \mathrm{mg}$ every other day (qod), which was increased to $1 \mathrm{mg}$ qod and $1.5 \mathrm{mg}$ qod after 5 and 10 days respectively. If UFC remained elevated, ketoconazole ( $200 \mathrm{mg}$ tid) was added to pasireotide and cabergoline at day 60 . The last evaluation was performed at day 80 , after which patients could choose either to continue medical therapy or to proceed to transsphenoidal adenomectomy or radiotherapy. The protocol was approved by the Ethics Committees of all participating centers. Each participant of the study gave written informed consent.

The results with respect to UFC excretion are outlined in a previous study (13). In short, pasireotide monotherapy induced sustained normalization of UFC in 5/17 patients (29\%) at day 28 . The addition of cabergoline normalized UFC excretion in an additional 4/17 patients (24\%) after a month of combination therapy. At day 60, 
low-dose ketoconazole was initiated in 8/17 patients who still had elevated UFC with pasireotide-cabergoline combination therapy. Addition of ketoconazole induced biochemical remission in six of these eight patients at day 80 , increasing the percentage of patients with a complete response to $88 \%$.

At baseline, serum potassium concentrations were normal and 13 of 17 patients used antihypertensive drugs (Table 1). Two patients were using oral contraceptives; one patient was in the postmenopausal phase with low estrogen levels and concomitant elevated FSH/LH levels; and in one patient, FSH/LH were elevated, while estrogen was still normal. Throughout the study period, all drugs were stopped in two patients (although an AT1 receptor antagonist was restarted in one of them (patient 7 in Table 1) at day 80), while dose reductions were applied in five other patients. Compared with baseline, the dosage of antihypertensive drugs had been increased in one patient at day 80; one patient received an extra antihypertensive agent at day 56, and in one patient, the thiazide diuretic was stopped and the dosage of doxazosin was increased from day 80 onwards. In one patient, the AT1 receptor antagonist was stopped, while the dosage of spironolactone was increased at day 80. Finally, the amount and dosage of antihypertensive drugs did not change at day 80 compared with baseline in two patients. Of note, two patients (patients 7 and 9 in Table 1) experienced pulmonary embolism in the initial study phase and were treated with low-molecular weight heparin and vitamin $\mathrm{K}$ antagonists. At follow-up (average of 4.0 years after day 80 , range 3.3-4.7 years), blood was collected from nine patients who were all in biochemical remission after transsphenoidal surgery $(n=7)$ or with ketoconazolecabergoline combination therapy $(n=2)$. Four of these patients did not use antihypertensive drugs, two used a $\beta$-adrenoceptor blocker, one used a combination of an AT1 receptor antagonist and a thiazide diuretic, one used a combination of amiloride and a thiazide diuretic, and the last patient used an angiotensin-converting enzyme (ACE) inhibitor, an AT1 receptor antagonist and a $\beta$-adrenoceptor blocker.

\section{Blood pressure measurement}

Blood pressure was measured when patients were in a resting state. Six consecutive measurements were performed during $30 \mathrm{~min}$ using an automatic oscillometric device, and the mean of these values was used in the analysis.

\section{Hormone measurements}

UFC was measured in a central laboratory using HPLC as described previously (13) (ULN: $145 \mathrm{nmol} / 24 \mathrm{~h}$ ).

Blood was sampled after an overnight fast, with the patient in supine position. Angiotensinogen (reference value $1100-1700 \mathrm{pmol} / \mathrm{ml}$; interassay variability $10 \%$ ) was measured as the maximum quantity of Ang I that was generated during incubation with excess recombinant renin (18). Aldosterone (reference value $50-150 \mathrm{pg} / \mathrm{ml}$; interassay variability $8.4 \%$ ) was measured by solid-phase RIA (Siemens Healthcare Diagnostics Ltd, Los Angeles, CA, USA). Renin (reference value $5-25 \mathrm{pg} / \mathrm{ml}$; interassay variability $7.2 \%$ ) was measured using a RIA (Cisbio Bioassays, Codolet, France). ET-1 (reference value $1.0-4.9 \mathrm{pg} / \mathrm{ml}$; interassay variability $7.1 \%$ ) was measured using the Human ET-1 QuantiGlo ELISA Kit (R\&D Systems, Abingdon, Oxon, UK). NT-proBNP (reference value $<15 \mathrm{pmol} / \mathrm{l}$ ) was measured to estimate volume status using a commercially available immunoassay (Elecsys ProBNP, Roche Diagnostics).

\section{Animals}

Three-month-old WKY male rats (body weight $324 \pm 16 \mathrm{~g}$; $n=8$ ) and SHR (body weight: $302 \pm 14 \mathrm{~g} ; n=32$ ) were obtained from Charles River (Cologne, Germany). All of the experiments were performed under the regulation and permission of the animal care committee of the Erasmus MC.

\section{Tissue collection}

Rats were euthanized with pentobarbital (60 mg/kg i.p.). Subsequently, iliac arteries were removed, prepared, and ring segments were mounted in Mulvany myographs.

\section{Mulvany myographs}

Iliac arteries were cut into ring segments of 2-mm length and mounted in a Mulvany myograph with separated 6-ml organ baths containing gassed $\left(95 \% \mathrm{O}_{2} / 5 \% \mathrm{CO}_{2}\right)$ KrebsHenseleit buffer at $37^{\circ} \mathrm{C}$. No antioxidants were added. The tension was normalized to $90 \%$ of the estimated diameter of $100 \mathrm{mmHg}$ effective transmural pressure (19). After a 30-min stabilization period, the maximal contractile response was determined by exposing the vessels to $100 \mathrm{mmol} / \mathrm{l}$ of $\mathrm{KCl}$. Thereafter, the vessels were preincubated for $30 \mathrm{~min}$ in fresh buffer in the absence or presence of pasireotide, octreotide, cabergoline (all $10 \mathrm{nmol} / \mathrm{l}(20)$ ), 


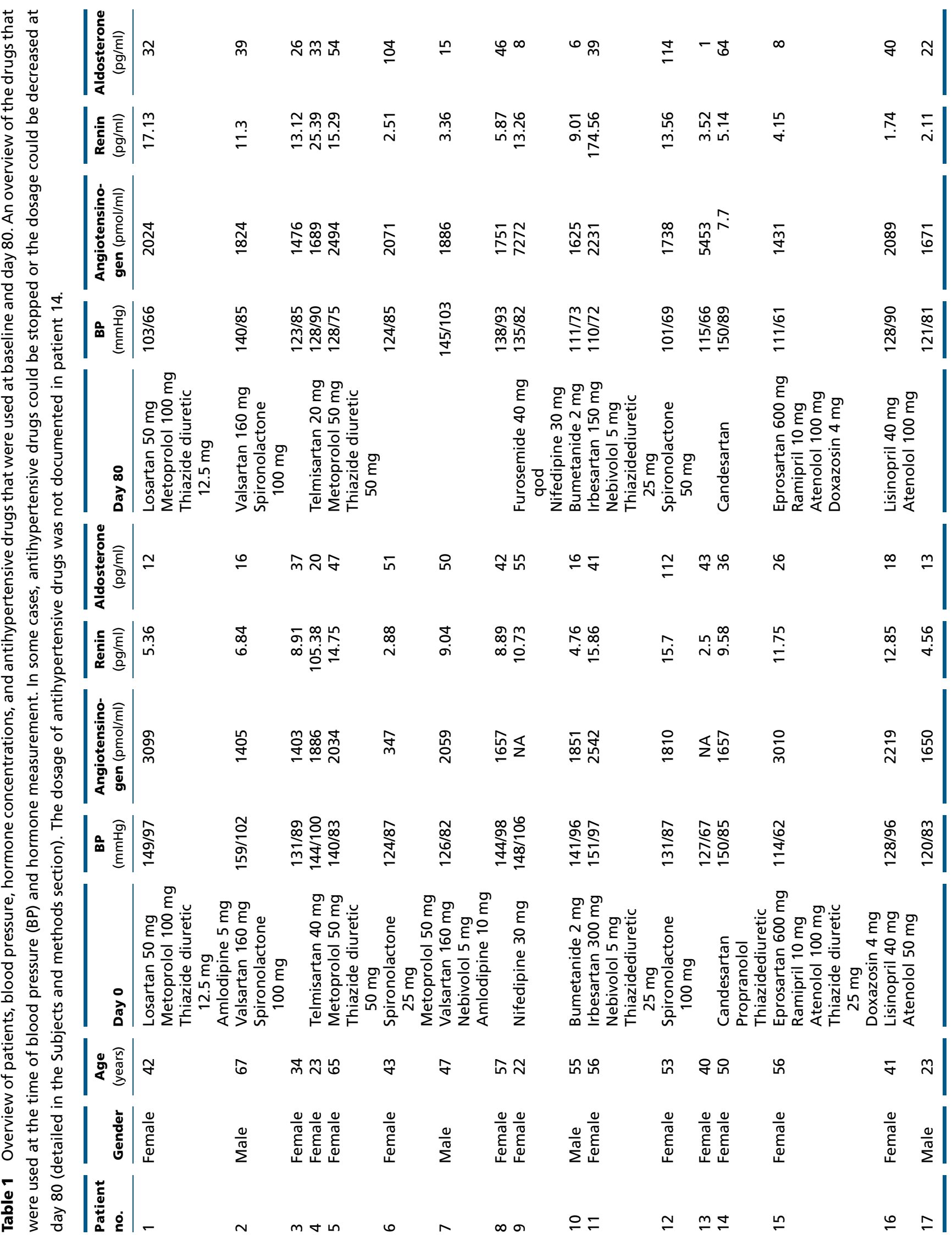


hydrocortisone (10 $\mu \mathrm{mol} / \mathrm{l}$; GR agonist with MR affinity), and dexamethasone ( $1 \mu \mathrm{mol} / \mathrm{l}$; GR agonist). The latter concentrations were chosen to ascertain maximal GR/MR stimulation. Subsequently, concentration-response curves were constructed to Ang II as described previously (21).

\section{Statistical analysis}

Data were analyzed using SPSS 15.0 for Windows. To compare values at baseline with those at day 28 and 80 , the Wilcoxon signed-ranks test was used. Two-way ANOVA was used to compare the maximum effect of Ang II in treated and untreated vessels in Mulvany myographs. Spearman's $\rho$ was calculated for correlation analysis. Statistical significance was accepted at the 0.05 level of probability.

\section{Results}

\section{RAAS components, ET-1, and NT-proBNP at baseline}

Before the start of medical treatment, plasma concentrations of angiotensinogen $(1880 \pm 161 \mathrm{pmol} / \mathrm{ml}$ (mean \pm S.E.M.)) were elevated, whereas the concentrations of renin $(13.7 \pm 5.83 \mathrm{pg} / \mathrm{ml})$ and aldosterone $(37.2 \pm 1.03 \mathrm{pg} / \mathrm{ml})$ were in the low-normal range or even below the normal range (Fig. 1). Mean plasma levels of ET-1 (1.6 \pm $0.14 \mathrm{pg} / \mathrm{ml})$ and NT-proBNP $(5.9 \pm 0.68 \mathrm{pmol} / \mathrm{l})$ were in the low-normal range at baseline. There were no differences in angiotensinogen, renin, or aldosterone concentrations among patients treated with AT1 receptor antagonists, ACE-inhibitors, or $\beta$-adrenoceptor blockers, respectively, and patients who were not.

\section{Treatment effects}

During treatment, systolic blood pressure decreased from $136.9 \pm 12.7$ to $124.2 \pm 14.4 \mathrm{mmHg}$ at day $80(P<0.01)$ and diastolic blood pressure from $89.2 \pm 11.8$ to $80.3 \pm$ $11.4 \mathrm{mmHg}$ (Fig. 2; $P<0.01$ ). Change in systolic or diastolic blood pressure among the three treatment groups did not differ (data not shown). Body weight decreased from $85.9 \pm 18.9$ to $83.8 \pm 18.2 \mathrm{~kg}$ at day $80(P<0.05)$.

Plasma concentrations of angiotensinogen, renin, and aldosterone did not change throughout the study period in the whole patient group nor in the subgroups of patients with or without the use of ACE-inhibitors, AT1 receptor antagonists, or MR antagonists. The aldosterone:renin ratio at baseline was $5.0 \pm 1.2$ and at day 80 it was $7.3 \pm 2.6$ (NS). ET-1 increased at day 80 compared with baseline $(P<0.05)$. Similarly, NT-proBNP was higher at both day $28(P<0.05)$ and day $80(P<0.01)$ compared with baseline, although its concentration was still in the normal range (Fig. 1; Supplementary Figure 1, see section on supplementary data given at the end of this article, for individual patient data).

One patient showed a strong increase in renin concentration (from $15.8 \mathrm{pg} / \mathrm{ml}$ at baseline to $174.6 \mathrm{pg} / \mathrm{ml}$ at day 80 ), which was accompanied by a marked decrease in blood pressure (from 151/97 to $110 / 72 \mathrm{mmHg}$ ). This patient needed triple therapy (pasireotide, cabergoline, and ketoconazole) to reach normal UFC levels, indicating that throughout the study
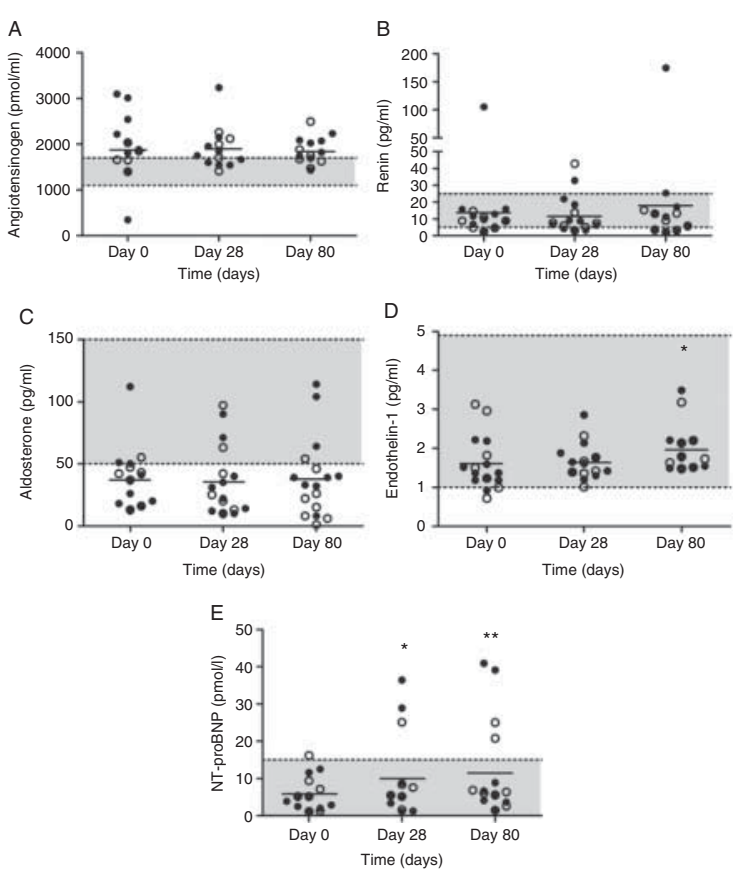

\section{Figure 1}

Individual plasma concentrations of $(A)$ angiotensinogen, (B) renin, (C) aldosterone, (D) ET-1, and (E) NT-proBNP in 17 patients with $C D$ throughout the study period. Solid circles represent concentrations of patients who were using RAAS blockers, i.e. AT1 receptor antagonists, ACE-inhibitors, or MR antagonists. Open circles represent plasma concentrations of patients who were not using these drugs. Bars indicate mean plasma concentrations. The intervals that are filled (light grey) represent reference ranges. ${ }^{*} P<0.05$ compared with baseline; $* * P<0.01$ compared with baseline. Two patients were excluded from the angiotensinogen analysis because they were using oral contraceptives, which are well-known to increase plasma concentrations of angiotensinogen (47). 


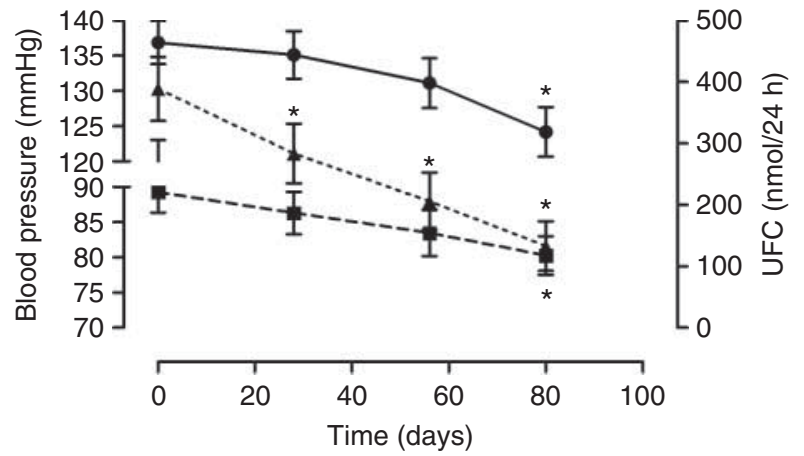

Figure 2

Course of systolic and diastolic blood pressure and UFC excretion throughout the 80-day study period. Circles and solid line, systolic blood pressure; squares and dashed line: diastolic blood pressure; triangles and dashed line, UFC excretion. Data represent mean \pm S.E.M. ${ }^{*} P<0.01$ compared with baseline.

period, her cortisol levels were high. She complained about myalgia and arthralgia throughout the study period and these symptoms had not changed at day 80 compared with baseline. After the start of ketoconazole, her cortisol excretion normalized. However, she also developed nausea, dizziness, and headache after initiation of ketoconazole. Presumably, these symptoms were side effects of ketoconazole rather than signs of adrenal insufficiency. At day 80, her sodium level was
$140 \mathrm{mmol} / \mathrm{l}$, potassium level was $4.1 \mathrm{mmol} / \mathrm{l}$, morning cortisol was $1115 \mathrm{nmol} / \mathrm{l}$, ACTH was $176 \mathrm{pmol} / \mathrm{l}$, and UFC was $67 \mathrm{nmol} / 24 \mathrm{~h}$ (upper limit of normal: $145 \mathrm{nmol} / 24 \mathrm{~h}$ ). The patient did not receive GCs.

Plasma concentrations of angiotensinogen, renin, and aldosterone were evaluated again in nine of 17 patients who were in remission for a mean period of 4.0 years (range 3.3-4.7 years). The mean blood pressure in these patients was 135.8/83.8 $\mathrm{mmHg}$; five had a systolic blood pressure $>140 \mathrm{mmHg}$ and three had a diastolic blood pressure $>90 \mathrm{mmHg}$. Despite long-term biochemical remission, plasma concentrations of angiotensinogen, renin, and aldosterone had not changed compared with either baseline or at day 80 (Fig. 3). With the exception of one patient, however, angiotensinogen levels appeared to move toward the normal range at this time. At follow-up, the aldosterone:renin ratio $(4.3 \pm 1.1)$ had not significantly changed compared with baseline. Again, no differences were found between patients who used AT1 receptor antagonists, ACE-inhibitors, or $\beta$-adrenoceptor blockers, respectively, and patients who were not.

\section{Correlations}

At baseline, there were no significant correlations between UFC excretion and blood pressure. UFC excretion was negatively associated with plasma concentrations of aldosterone $(r=-0.59 ; P<0.05)$ and, although not
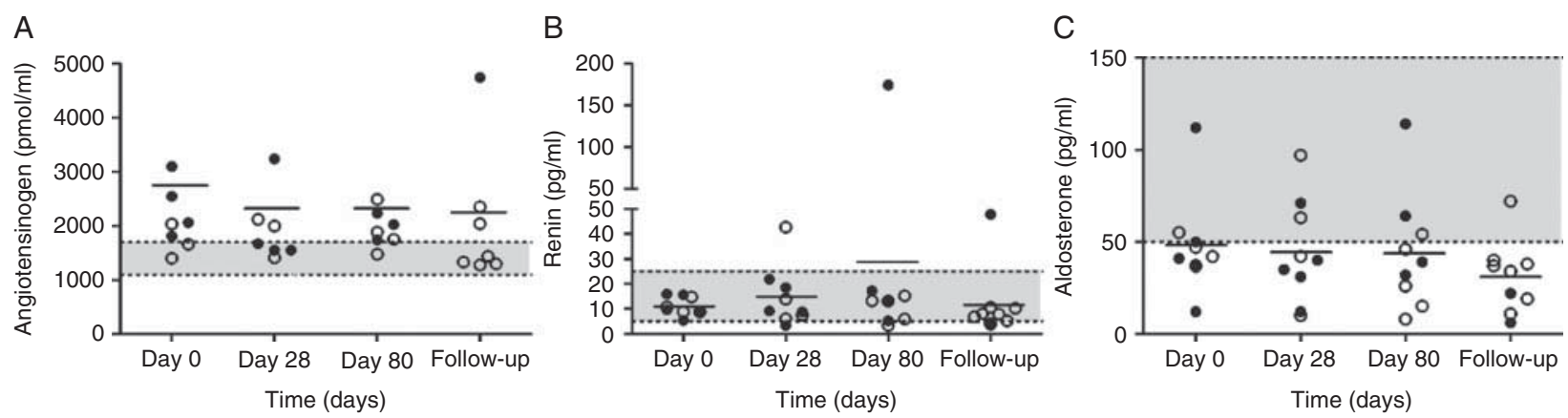

\section{Figure 3}

Individual plasma concentrations of $(\mathrm{A})$ angiotensinogen, (B) renin, and (C) aldosterone in nine patients throughout the study period. Solid circles represent concentrations of patients who were using RAAS blockers, i.e. AT1 receptor antagonists, ACE inhibitors, or MR antagonists. Open circles represent plasma concentrations of patients who were not using these drugs. Bars indicate mean plasma concentrations. The intervals that are filled (light grey) represent reference ranges. One patient was excluded from the angiotensinogen analysis because she was using an oral contraceptive, which is wellknown to increase plasma concentrations of angiotensinogen (47). Follow-up: mean of 4.0 years (range 3.3-4.7 years) of biochemical remission. 
statistically significant, with renin $(r=-0.42 ; P=0.09)$. No correlation was found between UFC excretion and angiotensinogen or between blood pressure and either RAAS component. Baseline ET-1 concentrations were correlated with both systolic $(r=0.51 ; P<0.05)$ and diastolic $(r=0.60 ; P<0.05)$ blood pressure. Changes in blood pressure and the changes in UFC excretion at day 28 and 80 compared with baseline were not correlated. Finally, there was a significant correlation between BMI and angiotensinogen concentrations $(r=0.56 ; P<0.05)$.

\section{Mulvany myographs}

Ang II induced a dose-dependent vasoconstriction of iliac arteries of the SHR and the WKY. In SHR, but not WKY rats (data not shown), octreotide reduced the Ang II-mediated vasoconstriction compared with controls (at $3(P<0.05), 10$, and $30 \mathrm{nM}$ (both $P<0.01$ ) of Ang II; Fig. 4A). Similar trends were observed for pasireotide and cabergoline (Fig. 4A).

In order to mimic the combined AT1 receptor-GR/MR stimulation that potentially occurs in vivo in CD patients, we subsequently evaluated the effects of pasireotide, octreotide, or cabergoline in the presence of $1 \mu \mathrm{mol} / 1$ dexamethasone or $10 \mu \mathrm{mol} / 1$ hydrocortisone on the Ang II response in SHR.

Neither dexamethasone nor hydrocortisone altered the Ang II response. When given on top of dexamethasone, pasireotide $(P<0.05)$ and octreotide $(P<0.01)$ inhibited the Ang II-mediated vasoconstriction compared with dexamethasone alone, whereas no such effects were seen with cabergoline (Fig. 4B).

When given on top of hydrocortisone, neither pasireotide, nor octreotide or cabergoline affected the Ang II responses, although the trend observed for octreotide was identical to that observed with Ang II alone or Ang II and dexamethasone (Fig. 4C).

\section{Discussion}

In this study, we report that hypertension in $\mathrm{CD}$ is associated with changes in the RAAS, characterized by elevated plasma angiotensinogen concentrations but low plasma concentrations of renin and suppressed aldosterone concentrations. Notably, renin levels were also low in patients using RAAS-inhibiting drugs, whereas aldosterone levels were also suppressed in patients treated with MR antagonists. Short-term biochemical remission induced by medical therapy was accompanied by a concomitant decrease in systolic and diastolic blood pressure without changes in plasma concentrations of angiotensinogen, renin, or aldosterone. Remarkably, the changes in RAAS components were still present after a long-term remission. In vitro, we found that in the presence of dexamethasone, pasireotide and octreotide both inhibit the Ang IIstimulated vasoconstriction of the iliac artery of the SHR.

The pathogenesis of GC-induced hypertension is multifactorial and one of the involved mechanisms includes modifying effects of GC excess on the RAAS.
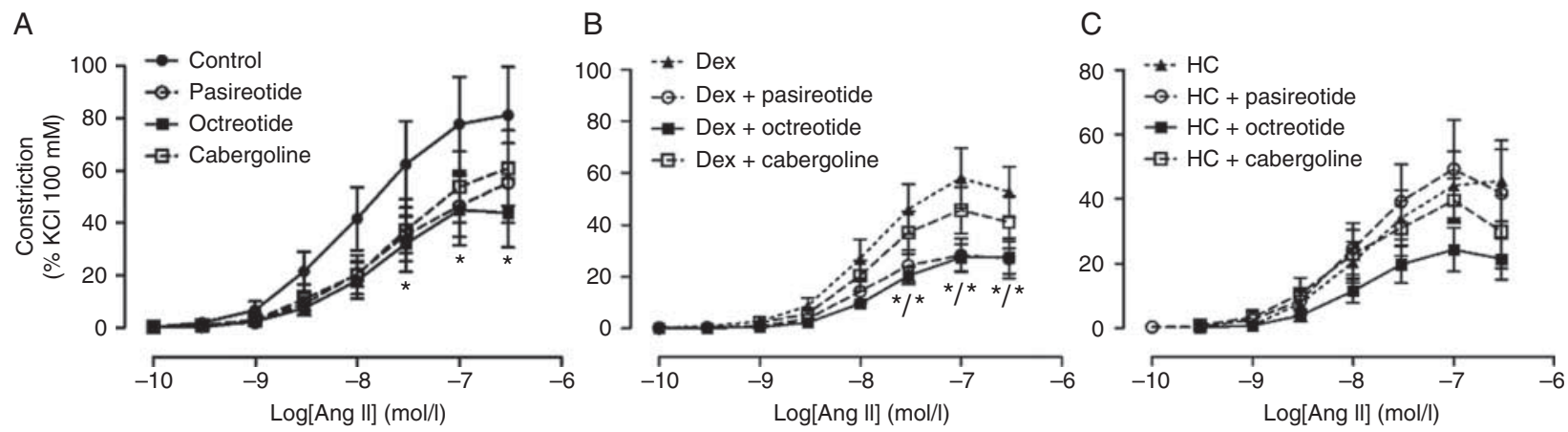

\section{Figure 4}

Effects of angiotensin II (Ang II) in iliac arteries of SHRs in the absence or presence of pasireotide, octreotide, cabergoline (all at $10 \mathrm{nM}$ ), dexamethasone (Dex; $1 \mu \mathrm{M})$, or hydrocortisone (HC; $10 \mu \mathrm{M}$ ). (A and B) $n=8$; (C) $n=6$. Data (mean \pm S.E.M.) are expressed as a $\%$ of the response to $\mathrm{KCl} 100 \mathrm{mM}$. *Significant inhibitory effect compared with control/dexamethasone; */* the effect is statistically significant for both pasireotide and octreotide. Levels of significance are indicated in the Results section. 
First, elevated cortisol concentrations can exceed the capacity of renal $11 \beta$-hydroxysteroiddehydrogenase type II, resulting in cortisol-mediated activation of the MR (3). Frank edema and hypokalemia most frequently occur in patients with ectopic ACTH production and very high cortisol levels, but not in patients with CD (11). Second, GC can induce increases in angiotensinogen levels (22), thus potentially stimulating RAAS activity. Third, GC has been reported to enhance the vasopressor activity of Ang II. In patients with CD, an increased response to Ang II infusion has been described (4). An explanation for this finding was provided by a study showing that dexamethasone stimulated the mRNA expression of the AT1 receptor in vascular smooth muscle cells from the aorta of WKY rats, an effect that was counteracted by the GR antagonist, mifepristone (23).

Only a limited number of studies reported plasma concentrations of renin and aldosterone in CS $(4,5,9,24$, $25,26,27)$. Compared with patients with the metabolic syndrome and controls, renin and aldosterone concentrations were not different among patients with CS in one study (25). In agreement with this observation, another study found plasma renin activity and aldosterone concentrations to be in the normal range in patients with CS (24). In contrast, plasma renin concentrations were elevated in patients with $\mathrm{CD}$, while aldosterone levels were in the low-normal range in another study (9). However, suppressed plasma renin activity and renin concentration have also been reported in CS $(4,5)$. In our series of $17 \mathrm{CD}$ patients, we found low and suppressed baseline plasma concentrations of renin and aldosterone, respectively, in virtually all patients. This observation suggests that hypertension in CD is not renin-mediated, but does not rule out the possibility of increased MR activity due to elevated cortisol concentrations, exceeding the capacity of $11 \beta$-hydroxysteroiddehydrogenase type II to converse cortisol into cortisone. The inverse association between UFC and renin and aldosterone levels indeed suggests renin inhibition and, subsequently, aldosterone production via cortisol-mediated MR stimulation, although the low-normal NT-proBNP levels do not indicate volume overload in our patients. In addition, the MR antagonist spironolactone could not prevent GC-induced hypertension in healthy volunteers (28), suggesting that other mechanisms are also involved.

We acknowledge that our patients used a variety of antihypertensive drugs throughout the study period, most of which are known to interfere with plasma concentrations of renin and aldosterone. Although this is an obvious limitation of our study, we believe that the observed renin and aldosterone concentrations in patients with RAAS blockade strengthen our conclusions, because AT1 receptor antagonists and ACE inhibitors normally increase renin 1.3- to 2 -fold (29). Although renin concentrations are generally suppressed by the use of $\beta$-adrenoceptor blockers (30), no additive renin-lowering effect was observed in our patients who were using these drugs. Still, it has to be emphasized that the effects of various combinations of antihypertensive drugs (as used by several of our patients) on plasma concentrations of renin and aldosterone are unknown. Therefore, future studies that aim to prospectively investigate the effects of (medical) treatment on the RAAS in CD should only include patients using antihypertensive drugs that do not interfere with the RAAS, e.g. $\alpha$-adrenoceptor blockers.

The discrepancy between previous studies that reported normal/elevated renin levels in patients with CS $(6,7,8,9)$ and our results might be explained by differences in the sample conditions (e.g. supine vs upright position). In addition, applying renin activity assays in the presence of elevated angiotensinogen levels may result in overestimation of renin levels (31). It is important to note that we measured renin directly (making use of an active site-directed antibody), i.e. independently of the level of endogenous angiotensinogen. Normally, measurements of renin activity and concentration run in parallel, except under conditions where endogenous angiotensinogen is very low (like in heart failure) or high (like in this study).

Another limitation of our study is the fact that we did not measure our patients' sodium intake/excretion. Activity of the RAAS is partially dependent on a patient's sodium excretion and therefore, it is unknown in which way our results are influenced by this factor. Finally, it should be noted that blood pressure, although measured in a standardized way, was not evaluated with ambulatory blood pressure monitoring.

The elevated baseline angiotensinogen level might represent a second explanation for the low renin concentrations, i.e. decreased renin levels could compensate for the elevated angiotensinogen levels to prevent excess production of Ang I and Ang II and, subsequently, a further rise in blood pressure (31). Renin levels are indeed lower in subjects with elevated angiotensinogen levels due to a gene polymorphism or estrogen use, suggesting a negative feedback mechanism $(16,31,32)$. The increased angiotensinogen concentration might be a direct effect of excessive GC production, which apparently is more important than the angiotensinogen-lowering effect of RAAS blockade (33). Klett et al. (22) demonstrated 
that treatment with dexamethasone results in a rapid increase in hepatic angiotensinogen mRNA expression and, consequently, angiotensinogen protein levels in rats.

Plasma concentrations of ET-1, a powerful vasoconstrictor, were previously found to be elevated in patients with CS (34). We could not confirm a contributory role of ET-1 in the pathogenesis of hypertension in CD, as we found low-normal plasma concentrations.

This study is the first to report the effects of medical treatment of $\mathrm{CD}$ on circulating components of the RAAS. Despite biochemical remission and a decrease in blood pressure after medical combination therapy, plasma angiotensinogen concentration remained elevated, while renin and aldosterone concentrations remained low in most patients, also at long-term follow-up. Hypertension persists in $\sim 25-50 \%$ of the patients with CD after surgical cure (2). This indicates that hypertension might partially be irreversible and/or caused by factors other than hypercortisolism. As angiotensinogen levels are also elevated in obesity (35) and as angiotensinogen even may be produced by visceral adipose tissue (36), persistence of abdominal obesity may contribute to persistently elevated angiotensinogen levels in cured CD patients. In agreement with this, we found a correlation between BMI and plasma angiotensinogen levels, both at baseline and at the end of the study period.

Apart from the elevated angiotensinogen concentrations, the lack of an increase in renin and aldosterone plasma concentrations when patients were in remission might theoretically be caused by direct inhibitory effects of pasireotide and cabergoline. In rats, treatment with endogenous somatostatin, but also with octreotide, has been demonstrated to decrease the volume of the adrenal zona glomerulosa and, consequently, serum concentrations of aldosterone. In contrast, the zona fasciculata and zona reticularis were not affected by somatostatin treatment in these studies $(37,38)$. Another study showed stimulatory effects of a somatostatin receptor antagonist on plasma renin activity and aldosterone concentrations in rats, an effect that was neutralized by concomitant treatment with somatostatin itself. Somatostatin alone, however, did not influence renin or aldosterone in these animals (39).

The dopamine subtype 2 receptor $\left(\mathrm{D}_{2} \mathrm{R}\right)$ antagonist, metoclopramide, has been shown to increase baseline aldosterone levels and the Ang II-stimulated increase in aldosterone concentration in both rats and humans on a high sodium diet. These effects were counteracted by dopamine and were not observed in subjects on a normal sodium diet, suggesting that aldosterone secretion is under tonic dopaminergic control (40). Quinagolide, a $\mathrm{D}_{2} \mathrm{R}$ agonist, did not affect plasma concentrations of renin or aldosterone in 12 subjects treated for macroprolactinomas, but concentrations of both hormones did increase after metoclopramide stimulation, again suggesting that $\mathrm{D}_{2} \mathrm{R}$ stimulation suppresses the RAAS (41). In vitro, cabergoline inhibited the aldosterone secretion in primary cultures of human adrenal glands (42). Taken together, the use of cabergoline could have contributed to the lack of increase in aldosterone concentrations after blood pressure normalization.

ET-1 levels increased throughout the study period, although remaining in the normal range. This observation contrasts to the reported decrease in ET-1 concentration, although not statistically significant, after successful surgery for CS (34). This discrepancy may be explained by different follow-up periods or, although speculative, by direct effects of our study medication.

Although the decrease in blood pressure following biochemical remission might well be explained by the normalization of cortisol concentrations, we investigated whether pharmacological concentrations of somatostatin analogs and cabergoline also have a direct vasodilatory effect. In a previous study, it has been reported that human arterial endothelial cells express somatostatin receptor subtype $2\left(\right.$ sst $\left._{2}\right)$, sst ${ }_{4}$, and especially sst ${ }_{1}(43)$. WKY rats have been reported to express all ssts in their aortic wall, both at mRNA and protein level (44). Another study showed $\mathrm{sst}_{2}$ protein expression in both the aorta and iliac artery of the WKY rat, while no sst ${ }_{3}$ and sst $_{5}$ expression could be detected (45). In addition, $\mathrm{D}_{2} \mathrm{R}$ binding sites have been found in rat arteries (46). In this study, the $s^{2} t_{2}$-preferring somatostatin analog octreotide reduced Ang II-mediated vasoconstriction of SHR iliac arteries, whereas no reductions were found for pasireotide and cabergoline. Yet pasireotide, like octreotide, did reduce Ang II-mediated vasoconstriction in the presence of dexamethasone, whereas carbergoline remained ineffective. This supports the concept that somatostatin analogs, but not $\mathrm{D}_{2} \mathrm{R}$ agonists, are particularly effective in counterbalancing vasoconstriction resulting from AT1 receptor-GR interaction. Similarly, GPR30 antagonists effectively prevent the aldosterone-induced potentiation of vasoconstriction in response to Ang II (17). These findings raise the possibility that pasireotide has directly contributed to the decrease in blood pressure in our patients. However, we do realize that these results were obtained in an animal model and cannot simply be extrapolated to the human situation. Additional experiments are therefore needed to further explore the role of somatostatin analogs in human vascular contractility. It should be noted that a similar inhibitory 
trend with octreotide was observed toward Ang II in the presence of the GR agonist hydrocortisone. This could relate to the fact that hydrocortisone, at the applied concentration of $10 \mu \mathrm{M}$, also induces NO release, thereby partially counteracting Ang II-induced vasoconstriction (17). Obviously, decreases on top of an already diminished response are more difficult to demonstrate.

In conclusion, hypertension in patients with $\mathrm{CD}$ is characterized by low/suppressed plasma concentrations of renin and aldosterone, even when patients are treated with RAAS blockers. Low renin and aldosterone concentrations may result from elevated angiotensinogen levels and feedback inhibition by high circulating cortisol levels acting via the MR. Despite normalization of both cortisol levels and blood pressure after short-term medical combination therapy, no changes occurred in angiotensinogen, renin, and aldosterone plasma concentrations. Finally, pasireotide may have a direct blood pressure-lowering effect.

\section{Supplementary data}

This is linked to the online version of the paper at http://dx.doi.org/10.1530/ EJE-13-0477.

\section{Declaration of interest}

S W J Lamberts and R A Feelders have performed consultancy activities for Novartis.

\section{Funding}

This is an investigator-initiated clinical trial sponsored by Novartis Pharma, Basel, Switzerland.

\section{References}

1 Newell-Price J, Bertagna X, Grossman AB \& Nieman LK. Cushing's syndrome. Lancet 2006367 1605-1617. (doi:10.1016/S01406736(06)68699-6)

2 Feelders RA, Pulgar SJ, Kempel A \& Pereira AM. The burden of Cushing's disease: clinical and health-related quality of life aspects. European Journal of Endocrinology 2012167 311-326. (doi:10.1530/EJE-11-1095)

3 Magiakou MA, Smyrnaki P \& Chrousos GP. Hypertension in Cushing's syndrome. Best Practice \& Research. Clinical Endocrinology \& Metabolism 200620 467-482. (doi:10.1016/j.beem.2006.07.006)

4 Saruta T, Suzuki H, Handa M, Igarashi Y, Kondo K \& Senba S. Multiple factors contribute to the pathogenesis of hypertension in Cushing's syndrome. Journal of Clinical Endocrinology and Metabolism $1986 \mathbf{6 2}$ 275-279. (doi:10.1210/jcem-62-2-275)

5 Mantero F, Armanini D \& Boscaro M. Plasma renin activity and urinary aldosterone in Cushing's syndrome. Hormone and Metabolic Research 197810 65-71. (doi:10.1055/s-0028-1093484)

6 Krakoff L, Nicolis G \& Amsel B. Pathogenesis of hypertension in Cushing's syndrome. American Journal of Medicine 197558 216-220. (doi:10.1016/0002-9343(75)90572-0)
7 Ganguly A, Weinberger MH \& Grim CE. The renin-angiotensinaldosterone system in Cushing's syndrome and pheochromocytoma. Hormone Research 198317 1-10. (doi:10.1159/000179668)

8 Ritchie CM, Sheridan B, Fraser R, Hadden DR, Kennedy AL, Riddell J \& Atkinson AB. Studies on the pathogenesis of hypertension in Cushing's disease and acromegaly. Quarterly Journal of Medicine 199076 855-867.

9 Tenschert W, Baumgart P, Greminger P, Vetter W \& Vetter H. Pathogenetic aspects of hypertension in Cushing's syndrome. Cardiology 198572 (Suppl 1) 84-90. (doi:10.1159/000173950)

10 Atkinson AB, Kennedy A, Wiggam MI, McCance DR \& Sheridan B. Long-term remission rates after pituitary surgery for Cushing's disease: the need for long-term surveillance. Clinical Endocrinology 200563 549-559. (doi:10.1111/j.1365-2265.2005.02380.x)

11 van der Pas R, de Herder WW, Hofland L \& Feelders RA. New developments in medical therapy of Cushing's syndrome. EndocrineRelated Cancer 201219 R205-R223. (doi:10.1530/ERC-12-0191)

12 de Bruin C, Pereira AM, Feelders RA, Romijn JA, Roelfsema F, Sprij-Mooij DM, van Aken MO, van der Lelij AJ, de Herder WW, Lamberts SW et al. Coexpression of dopamine and somatostatin receptor subtypes in corticotroph adenomas. Journal of Clinical Endocrinology and Metabolism 200994 1118-1124. (doi:10.1210/ jc.2008-2101)

13 Feelders RA, de Bruin C, Pereira AM, Romijn JA, Netea-Maier RT, Hermus AR, Zelissen PM, van Heerebeek R, de Jong FH, van der Lely AJ et al. Pasireotide alone or with cabergoline and ketoconazole in Cushing's disease. New England Journal of Medicine 2010362 1846-1848. (doi:10.1056/NEJMc1000094)

14 Adams RL, Adams IP, Lindow SW \& Atkin SL. Inhibition of endothelial proliferation by the somatostatin analogue SOM230. Clinical Endocrinology 200461 431-436. (doi:10.1111/j.1365-2265.2004.02098.x)

15 Zarei S, Frieden M, Rubi B, Villemin P, Gauthier BR, Maechler P \& Vischer UM. Dopamine modulates von Willebrand factor secretion in endothelial cells via D2-D4 receptors. Journal of Thrombosis and Haemostasis 20064 1588-1595. (doi:10.1111/j.1538-7836.2006.01998.x)

16 Verdonk K, Durik M, Abd-Alla N, Batenburg WW, van den Bogaerdt AJ van Veghel R, Roks AJ, Danser AH \& van Esch JH. Compound 21 induces vasorelaxation via an endothelium- and angiotensin II type 2 receptor-independent mechanism. Hypertension 201260 722-729. (doi:10.1161/HYPERTENSIONAHA.112.196022)

17 Batenburg WW, Jansen PM, van den Bogaerdt AJ \& Danser AHJ. Angiotensin II-aldosterone interaction in human coronary microarteries involves GPR30, EGFR, and endothelial NO synthase. Cardiovascular Research 201294 136-143. (doi:10.1093/cvr/cvs016)

18 Danser AH, van Kesteren CA, Bax WA, Tavenier M, Derkx FH, Saxena PR \& Schalekamp MA. Prorenin, renin, angiotensinogen, and angiotensinconverting enzyme in normal and failing human hearts. Evidence for renin binding. Circulation 199796 220-226. (doi:10.1161/01.CIR. 96.1.220)

19 Mulvany MJ \& Halpern W. Contractile properties of small arterial resistance vessels in spontaneously hypertensive and normotensive rats. Circulation Research 197741 19-26. (doi:10.1161/01.RES.41.1.19)

20 de Bruin C, Hofland LJ, Nieman LK, van Koetsveld PM, Waaijers AM, Sprij-Mooij DM, van Essen M, Lamberts SW, de Herder WW \& Feelders RA. Mifepristone effects on tumor somatostatin receptor expression in two patients with Cushing's syndrome due to ectopic adrenocorticotropin secretion. Journal of Clinical Endocrinology and Metabolism 201297 455-462. (doi:10.1210/jc.2011-1264)

21 Moltzer E, Verkuil AV, van Veghel R, Danser AH \& van Esch JH. Effects of angiotensin metabolites in the coronary vascular bed of the spontaneously hypertensive rat: loss of angiotensin II type 2 receptormediated vasodilation. Hypertension 201055 516-522. (doi:10.1161/ HYPERTENSIONAHA.109.145037)

22 Klett C, Ganten D, Hellmann W, Kaling M, Ryffel GU, Weimar-Ehl T \& Hackenthal E. Regulation of hepatic angiotensinogen synthesis and secretion by steroid hormones. Endocrinology 1992130 3660-3668. (doi:10.1210/en.130.6.3660) 
23 Sato A, Suzuki H, Murakami M, Nakazato Y, Iwaita Y \& Saruta T. Glucocorticoid increases angiotensin II type 1 receptor and its gene expression. Hypertension 199423 25-30. (doi:10.1161/01.HYP.23.1.25)

24 Yasuda G, Shionoiri H, Umemura S, Takasaki I \& Ishii M. Exaggerated blood pressure response to angiotensin II in patients with Cushing's syndrome due to adrenocortical adenoma. European Journal of Endocrinology 1994131 582-588. (doi:10.1530/eje.0.1310582)

25 Zacharieva S, Kirilov G, Orbetzova M, Elenkova A, Shigarminova R, Lozanov V \& Mitev V. Homocysteine, renin and aldosterone in patients with Cushing's syndrome. Methods and Findings in Experimental and Clinical Pharmacology 200830 221-224. (doi:10.1358/mf.2008.30.3. 1159647)

26 Dalakos TG, Elias AN, Anderson GH Jr, Streeten DH \& Schroeder ET. Evidence for an angiotensinogenic mechanism of the hypertension of Cushing's syndrome. Journal of Clinical Endocrinology and Metabolism 197846 114-118. (doi:10.1210/jcem-46-1-114)

27 Bricaire H, Thibonnier M, Hautecouverture M, Corvol P \& Luton JP. [Variations of the renin aldosterone system in Cushing's disease (author's transl)] Variations du systeme renine angiotensine aldosterone dans la maladie de Cushing. La Nouvelle Presse Médicale 19809 1007-1009.

28 Montrella-Waybill M, Clore JN, Schoolwerth AC \& Watlington CO. Evidence that high dose cortisol-induced $\mathrm{Na}+$ retention in man is not mediated by the mineralocorticoid receptor. Journal of Clinical Endocrinology and Metabolism 199172 1060-1066. (doi:10.1210/ jcem-72-5-1060)

29 McKelvie RS, Yusuf S, Pericak D, Avezum A, Burns RJ, Probstfield J, Tsuyuki RT, White M, Rouleau J, Latini R et al. Comparison of candesartan, enalapril, and their combination in congestive heart failure: randomized evaluation of strategies for left ventricular dysfunction (RESOLVD) pilot study. The RESOLVD Pilot Study Investigators. Circulation 1999100 1056-1064. (doi:10.1161/01.CIR. 100.10.1056)

30 Ahmed AH, Gordon RD, Taylor P, Ward G, Pimenta E \& Stowasser M. Effect of atenolol on aldosterone/renin ratio calculated by both plasma renin activity and direct renin concentration in healthy male volunteers. Journal of Clinical Endocrinology and Metabolism 201095 3201-3206. (doi:10.1210/jc.2010-0225)

31 Danser AH, Derkx FH, Hense HW, Jeunemaitre X, Riegger GA \& Schunkert H. Angiotensinogen (M235T) and angiotensin-converting enzyme (I/D) polymorphisms in association with plasma renin and prorenin levels. Journal of Hypertension 199816 1879-1883. (doi:10.1097/00004872-199816121-00005)

32 Schunkert H, Danser AH, Hense HW, Derkx FH, Kurzinger S \& Riegger GA. Effects of estrogen replacement therapy on the reninangiotensin system in postmenopausal women. Circulation 199795 39-45. (doi:10.1161/01.CIR.95.1.39)

33 van den Heuvel M, Batenburg WW, Jainandunsing S, Garrelds IM, van Gool JM, Feelders RA, van den Meiracker AH \& Danser AH. Urinary renin, but not angiotensinogen or aldosterone, reflects the renal renin-angiotensin-aldosterone system activity and the efficacy of renin-angiotensin-aldosterone system blockade in the kidney. Journal of Hypertension 201129 2147-2155. (doi:10.1097/ HJH.Ob013e32834bbcbf)

34 Kirilov G, Tomova A, Dakovska L, Kumanov P, Shinkov A \& Alexandrov AS. Elevated plasma endothelin as an additional cardiovascular risk factor in patients with Cushing's syndrome. European Journal of Endocrinology 2003149 549-553. (doi:10.1530/ eje.0.1490549)

35 Kotsis V, Stabouli S, Papakatsika S, Rizos Z \& Parati G. Mechanisms of obesity-induced hypertension. Hypertension Research 201033 386-393. (doi:10.1038/hr.2010.9)

36 Boscaro M, Giacchetti G \& Ronconi V. Visceral adipose tissue: emerging role of gluco- and mineralocorticoid hormones in the setting of cardiometabolic alterations. Annals of the New York Academy of Sciences 20121264 87-102. (doi:10.1111/j.1749-6632.2012.06597.x)

37 Mazzocchi G, Robba C, Rebuffat P, Gottardo G \& Nussdorfer GG. Effect of somatostatin on the zona glomerulosa of rats treated with angiotensin II or captopril: stereology and plasma hormone concentrations. Journal of Steroid Biochemistry 198523 353-356. (doi:10.1016/ 0022-4731(85)90416-9)

38 Trifunovic S, Ajdzanovic V, Sosic-Jurjevic B, Filipovic B, Nestorovic N, Sekulic M \& Milosevic V. Multiple treatments with SRIH-14 or octreotide affect adrenal zona glomerulosa in adult male rats. General Physiology and Biophysics 200827 159-163.

39 Mazzocchi G, Malendowicz LK, Meneghelli V \& Nussdorfer GG. Evidence that endogenous somatostatin (SRIF) exerts a tonic inhibitory effect on the rat renin-angiotensin-aldosterone system. In Vivo 19926 $9-12$.

40 Missale C, Lombardi C, De Cotiis R, Memo M, Carruba MO \& Spano PF. Dopaminergic receptor mechanisms modulating the reninangiotensin system and aldosterone secretion: an overview. Journal of Cardiovascular Pharmacology 198914 (Suppl 8) S29-S39.

41 Nickelsen T, Jungmann E, Althoff P, Schumm-Draeger PM \& Usadel KH. Treatment of macroprolactinoma with the new potent non-ergot D2dopamine agonist quinagolide and effects on prolactin levels, pituitary function, an the renin-aldosterone system. Results of a clinical longterm study. Arzneimittel-Forschung 199343 421-425.

42 Pivonello R, Ferone D, de Herder WW, de Krijger RR, Waaijers M, Mooij DM, van Koetsveld PM, Barreca A, De Caro ML, Lombardi G et al. Dopamine receptor expression and function in human normal adrenal gland and adrenal tumors. Journal of Clinical Endocrinology and Metabolism 200489 4493-4502. (doi:10.1210/jc.2003-031746)

43 Curtis SB, Hewitt J, Yakubovitz S, Anzarut A, Hsiang YN \& Buchan AM. Somatostatin receptor subtype expression and function in human vascular tissue. American Journal of Physiology. Heart and Circulatory Physiology 2000278 H1815-H1822.

44 Khare S, Kumar U, Sasi R, Puebla L, Calderon L, Lemstrom K, Hayry P \& Patel AY. Differential regulation of somatostatin receptor types 1-5 in rat aorta after angioplasty. FASEB Journal 199913 387-394.

45 Chen JC, Hsiang YN \& Buchan AM. Somatostatin receptor expression in rat iliac arteries after balloon injury. Journal of Investigative Surgery 199710 17-23. (doi:10.3109/08941939709032120)

46 Cavallotti C, Nuti F, Bruzzone P \& Mancone M. Age-related changes in dopamine D2 receptors in rat heart and coronary vessels. Clinical and Experimental Pharmacology \& Physiology 200229 412-418. (doi:10.1046/ j.1440-1681.2002.03677.x)

47 Goldhaber SZ, Hennekens CH, Spark RF, Evans DA, Rosner B, Taylor JO $\&$ Kass EH. Plasma renin substrate, renin activity, and aldosterone levels in a sample of oral contraceptive users from a community survey. American Heart Journal 1984107 119-122. (doi:10.1016/00028703(84)90144-3)

Received 7 June 2013

Revised version received 2 October 2013

Accepted 28 October 2013 